\title{
PRECONCEITO MAQUIADO: O RACISMO NO MUNDO FASHIONISTA E DA BELEZA
}

\author{
A MADE-UP PREJUDICE: RACISM IN THE FASHIONISM AND BEAUTY WORLD
}

\author{
Recebido em 09.09.2016. Aprovado em 17.11.2016 \\ Avaliado pelo sistema double blind review
}

DOI: http://dx.doi.org/10.12712/rpca.v10i4.818

\section{Mariana Luísa da Costa Lage}

mariana.lage@ufjf.edu.br

Universidade Federal de Juiz de Fora (UFJF), Juiz de Fora/MG, BRASIL

\section{Denis Alves Perdigão}

denis.perdigao@ufjf.edu.br

Universidade Federal de Juiz de Fora (UFJF), Juiz de Fora/MG, BRASIL

\section{Felipe Gouvêa Pena}

felipegouveap@hotmail.com

Universidade Federal de Minas Gerais (UFMG), Belo Horizonte/MG, BRASIL

\section{Matheus Arcelo Fernandes Silva}

matheus.arcelo@gmail.com

Universidade Federal de Minas Gerais (UFMG), Belo Horizonte/MG, BRASIL

\section{Resumo}

Neste artigo, analisou-se discursos sobre o blackface no mundo fashionista e da beleza a partir da busca pela representatividade e pelo protagonismo negro, em contraponto a uma liberdade de expressão artística do profissional da área. Foi investigado um caso de blackface publicado pela empresa de cosméticos Avon em sua rede social. O corpus de análise constituiu-se por discursos presentes nos comentários registrados na referida publicação. Os dados foram categorizados e analisados com base na vertente da análise crítica do discurso teorizada por Dijk (2012). Evidenciou-se que as práticas racistas continuam disseminadas na sociedade e seu reconhecimento ainda é dificultado por sua naturalização. Também foi evidenciado que a percepção do blackface como arte ou prática racista não está diretamente relacionada à cor da pele de quem a analisa, mas à sua percepção cognitiva embasada na sua cultura, experiência de vida, capacidade crítica, conhecimento histórico, entre outros fatores.

Palavras-chave: Blackface. Racismo. Hegemonia branca. Mundo fashionista.

\section{Abstract}

In this article, we analyzed speeches on blackface in the fashionism and beauty world from the demand for the black representation and protagonism as opposed to a artistic freedom of expression in the area. A case of blackface published by cosmetics company Avon in its social network was investigated. The analysis consisted of present speeches in the comments registered in that publication. Data were categorized and analyzed based on the aspect of critical discourse analysis theorized by Dijk (2012). It was evident that racist practices are still widespread in society and its recognition is still hampered by his naturalization. It was also shown that the perception of blackface as art or racist practice is not directly related to the skin color of the person who looks but your cognitive perception grounded in their culture, life experience, critical skills, historical knowledge, among other factors.

Keywords: Blackface. Racism. White hegemony. Fashionism world. 


\section{Um corpo pintado de arte ou de preconceito?}

No dia 16 de setembro de 2015, a Avon, através da rede social Facebook, publicou uma foto de uma modelo tirada pela maquiadora que a produziu indicando na legenda que a mesma era a vencedora da categoria 'Editorial' do Prêmio Avon de Maquiagem 2015. Esta premiação acontece há vinte anos e é dirigida exclusivamente a maquiadores profissionais brasileiros, ou estrangeiros residentes no Brasil há mais de cinco anos, como forma de valorizar o profissional da maquiagem elevando-o à posição de artista. O prêmio possui as seguintes categorias: artes cênicas, audiovisual, editorial, passarela, publicidade e social ${ }^{1}$. O trabalho vencedor da categoria 'Editorial' é da maquiadora Mychelle Pavão e recebeu o título 'Todos Somos Um'.

O editorial teve uma repercussão não esperada pela maquiadora e pela Avon. Isto porque dentre as fotos do editorial, há duas modelos brancas maquiadas com a intenção de reproduzir mulheres negras, sendo uma delas inspirada na modelo profissional Winnie Harlow (FIGURA 1), negra portadora de vitiligo, uma doença caracterizada pela perda da coloração da pele.

Figura 1. Winnie Harlow

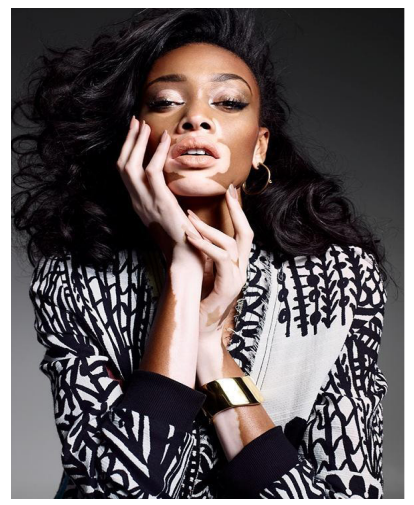

Fonte: Site Pessoal de Winnie Harlow² 2016.

Nas fotos do trabalho premiado, a modelo branca Nicole Lindner (FIGURA 2) está pintada com bases escuras no rosto, fazendo alusão à uma modelo negra portadora de vitiligo (FIGURA 3), enquanto a modelo

\footnotetext{
${ }^{1}$ Estas informações foram colhidas no site da $20^{\mathrm{a}}$ Edição do
} Prêmio Avon de Maquiagem, disponível no link: http://www. avon.com.br/novidades/destaques/20a-edicao-dopremio-avon-de-maquiagem

${ }^{2}$ Retirado de: http://chantellewinnie.com/portfolio/
Svetlana Kharlashkina - também branca - aparece maquiada como negra. A publicação, pela Avon, da foto da modelo Nicole Lindner maquiada como uma negra com vitiligo, em sua página na rede social, gerou muitas críticas e a repercussão negativa motivou a empresa a excluir a postagem apenas um dia após a sua publicação. No dia seguinte, 18 de setembro de 2015, a Avon postou sua justificativa para a publicação e desculpou-se com aqueles que podem ter se ofendido com a foto. A esta segunda publicação - de retratação - diversas pessoas se manifestaram denunciando a prática do blackface como racista enquanto outros defenderam o trabalho como expressão artística.

Diante desse contexto, esta pesquisa tem por objetivo analisar os diferentes posicionamentos discursivos manifestados por usuários de redes sociais sobre práticas denunciadas como racistas. Dessa forma, analisamos os discursos presentes nos comentários registrados na publicação de retratação da Avon. Como a postagem original foi retirada, tornou-se impossível tomar as manifestações associadas a ela como objeto de análise. Até a data de finalização da coleta de dados, a imagem havia sido curtida por 618 usuários, compartilhada por 23 usuários e recebido 211 comentários (incluindo réplicas e tréplicas).

Destaca-se que se entende que o gênero e a raça são socialmente construídos na e pela cultura, onde as relações de poder e os discursos historicamente construídos manifestam-se nos corpos num processo de organizing (SOUZA; COSTA; PEREIRA, 2015).

Figura 2 . Nicole Lindner

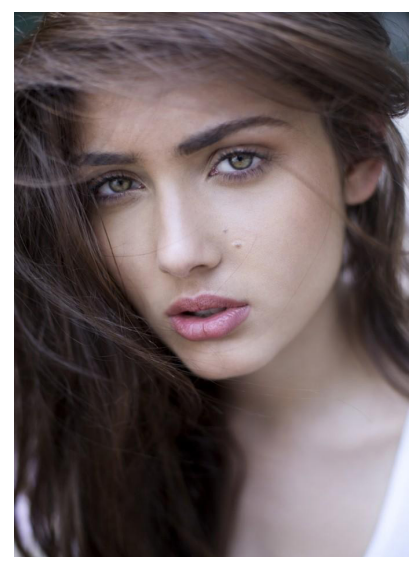

Fonte: Site da empresa Way Model³, 2016.

${ }^{3}$ Retirado de: http://www.waymodel.com.br/

blog/2014/10/shooting-nicole-lindner-2/ 
Figura 3 . Nicole Lindner no editorial premiado

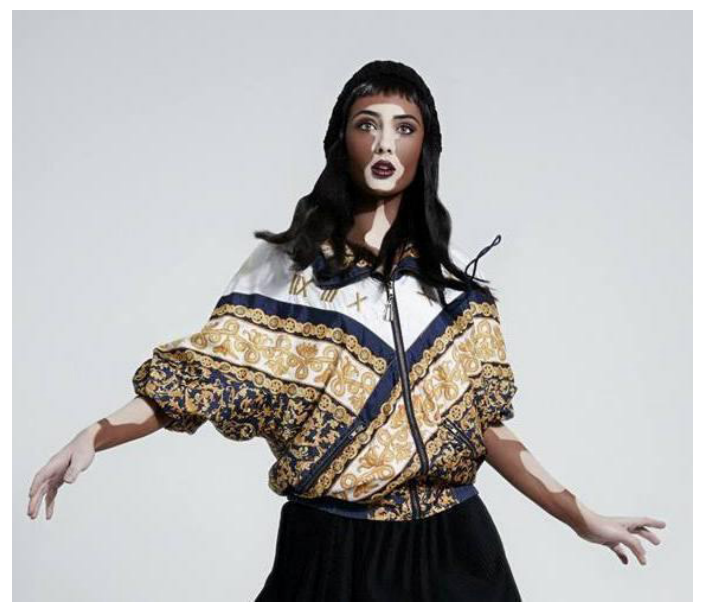

Fonte: Mychelle Pavão ${ }^{4}, 2016$

O artigo está estruturado nas seguintes seções: após esta introdução, discutimos sobre a hegemonia do padrão de beleza eurocêntrico, para posteriormente discutir os dilemas enfrentados pelas mulheres negras e o mercado fashionista e da beleza como espaço segregador. Em seguida, apresentamos o percurso metodológico; as análises dos resultados obtidos com a pesquisa; e, por fim, as considerações finais e as referências.

\section{A mulher negra e a estética branca hegemônica}

O ser humano é o único animal que transforma voluntariamente o próprio corpo, variando em nome da cultura ou de especificidades dos segmentos sociais de um mesmo grupo. Tais sinais impressos no corpo e o tipo de penteado podem transmitir informações como "hierarquia, idade, símbolo de status, de poder e de realeza", simbolizando o que a sociedade deseja ser ou negar (GOMES, 2003, p. 79). Isto acontece porque o padrão de beleza é "construído socialmente, num contexto histórico, cultural e político, e por isso mesmo pode ser ressignificado pelos sujeitos sociais" (GOMES, 2003, p. 75).

Chapman (2007) relata que os corpos das mulheres negras sempre foram um local para o discurso público, principalmente em relação ao padrão de beleza. No mundo ocidental, onde a estética branca

${ }^{4}$ Retirado de: https://www.facebook.com/photo. é hegemônica, a identidade negra foi construída para normalizar a brancura (JOHNSON; BANKHEAD, 2013). Assim, é a autoridade da estética branca quem define o "belo" e o "feio", e neste o negro é o oposto do belo (SOUZA, 1983, p. 29).

Braga (2015) faz uma descrição histórica e moderna do corpo da mulher negra através das variedades de "Vênus" - referente à deusa do amor e da fertilidade - que ao passar por diferentes culturas ao longo do tempo, acaba-se por significar a beleza, a virtude e o corpo da mulher.

A primeira delas, a Vênus de Willendorf, encontrada no período neolítico, é representada na escultura com seios e bacia hipertrofiados como símbolo da maternidade, como uma deusa-mãe. $\mathrm{Na}$ antiguidade clássica, há uma valorização dos atributos estéticos, tal como fizeram os gregos ao saudar a beleza feminina, de um corpo proporcional, porém ainda inferior ao do homem. Como o corpo viril do homem era domínio público, há uma transferência de atributos masculinos para os corpos femininos, como no caso da Vênus de Milo, cuja representação é musculosa, o abdômen é acentuado e os ombros largos, por exemplo. $\mathrm{Na}$ Idade Média, o corpo feminino representou o perigo, o demônio, assim como Eva ao encantar Adão, o que resultou em um forte medo e menos admiração. Em movimento contrário, na Idade Moderna, no renascimento, o corpo de demônio agora é visto como anjo, cujo patamar é superior ao do homem. Assim, há uma exaltação dos atributos físicos e espirituais da mulher, como retratado no quadro Nascimento de Vênus. Na passagem para o século XVI a representação se altera para um toque de sensualidade e apelo sexual, onde as pinturas retratam um feminino e sua autocontemplação, onde as mulheres estão admirando suas formas, como nas obras Vênus e sua Toalete, Vênus ao Espelho e Vênus Olhando-se ao Espelho. Estas "Vênus" traziam seu corpo moldado sempre à semelhança do belo, onde se confundiam beleza e corpo. Entretanto, o surgimento da Vênus negra ou Vênus Hotentote quebra esta relação, desvinculando o corpo da beleza (BRAGA, 2015).

Vênus negra é como ficou conhecida Saartjie Baartman, nascida na África do Sul e pertencente ao povo Hotentote, cujas características físicas como o 'avental frontal' (hipertrofia dos lábios vaginais), bem como a gordura nas nádegas, diferenciava-se do padrão europeu. Em 1810, Saartjie foi levada a Londres para ser exposta em feiras, circos e teatros, apresentando- 
se como uma selvagem, um monstro humano. A relação entre selvagem e civilizado, bem como o desenvolvimento do conhecimento científico pautado nas diferenças raciais e superioridade da raça branca, instaurou uma distância entre europeus e africanos. Além disso, embora a Vênus negra tenha atributos semelhantes à Vênus de Willendorf, ela não é cultuada em torno da fecundidade e sim de uma anormalidade e um alto grau de desejo sexual. Assim, a Vênus Hotentote representava a universalização de um corpo típico africano, cujo apetite sexual era incontrolável, criando o estereótipo da hipersexualidade da mulher negra. Seu corpo, atraído por cientistas para pesquisas ainda em vida, foi dissecado, conservado e exibido por quase dois séculos no Museu do Homem, em Paris, até que Nelson Mandela reivindicou que seus restos mortais retornassem à África (BRAGA, 2015).

Este fenômeno foi potencializado pelo processo escravocrata, onde as mulheres 'reais' eram as mulheres brancas. As normas de gênero reforçam estas hierarquias coloniais e impactam na construção social do padrão de feminilidade e beleza feminina (CHAPMAN, 2007). As características do comprimento e textura dos cabelos, o afinamento ou não do nariz, a cor dos olhos, acabam por criar visões opostas: de um lado mulheres dóceis e gentis e do outro, não apresentáveis e não atrativas (ROOKS, 1996). Assim, os povos de origem africana começam a acreditar que ter uma pele clara e um cabelo liso ajudaria a alcançar a mobilidade econômica e social (JOHNSON; BANKHEAD, 2013).

Adicionalmente, a mulher negra sofre duplamente em nossa sociedade sexista e racista, justamente por ser mulher e negra, o que a coloca numa posição inferior na hierarquia. O corpo é percebido nas mulheres negras nas disciplinas corporais, por exemplo, em se "fazer" o cabelo (CHAPMAN, 2007). Assim, Johnson e Bankhead (2013) apontam que saber quem você é e o que sente sobre você mesma, é uma questão essencial para a construção da identidade, e se tratando de mulheres negras, a identidade é associada principalmente a pele e ao cabelo.

\section{0 lugar (negado) da mulher negra no mercado fashionista e da beleza}

Sansone (1996), em sua pesquisa sobre o sistema de classificação da cor/raça, identificou que a autodeclaração da cor/raça ocorre de forma contingencial, pois variam com a classe social, a idade e principalmente o lugar. A partir desta perspectiva, o autor tipifica três lugares sociais que influenciam a autodeclaração, como eles enxergam a si mesmos e como avaliam e enfrentam a questão do preconceito e discriminação.

As áreas duras são o mercado de trabalho e, em particular, a procura do trabalho, o mercado matrimonial e da paquera e a relação com a polícia (SANSONE, 1996). Em geral, estes espaços são hegemonicamente brancos e onde a competição, a estética e o status deixam o negro em desvantagem (ROSA, 2011). As áreas moles são espaços onde o fato de ser negro não se torna um obstáculo e não envolve competição por status e poder, como nos espaços do lazer (botequim, forró) e religiosos (igrejas evangélicas, católicas e círculos espíritas) (SANSONE, 1996). Nestes espaços, evita-se falar em cor e racismo, tornando-se importante a convivência no compartilhamento dos espaços. Por fim, os espaços negros são lugares definidos e socialmente destinados para os negros, onde ser negro torna-se uma vantagem. Geralmente são lugares onde a cultura negra é a base das atividades, como no bloco-afro, nos terreiros de umbanda e candomblé e na capoeira (SANSONE, 1996).

Relacionando o mercado de trabalho das passarelas, Nunes (2013) destaca um aumento na tendência de valorização da África em contraste com o pequeno aumento no número de modelos negras contratadas. Para a coleção primavera/verão 2014, o site Jezebel analisou que durante a New York Fashion Week, de 4.637 looks, cerca de $80 \%$ eram de modelos brancas e apenas $8 \%$ negras. Ressalta-se que valores próximos a esta proporção também tem sido encontrados em outras estações (DRIES, 2013).

No Brasil, ainda que a população seja em sua maioria negra, o mesmo acontece. No ano de 2008, o Ministério Público do Estado de São Paulo (MP) abriu um inquérito para investigar uma possível prática discriminatória, onde apenas 3\% dos modelos eram negros (MANO, 2011). Como resultado da ação, o MP firmou um Termo de Ajustamento de Conduta (TAC) com a empresa organizadora do São Paulo Fashion Week para que no mínimo 10\% dos modelos fossem negros e indígenas. No entanto, em 2015, com o TAC findado, a ONG Educafro denuncia que a prática de exclusão retorna (BORGES, 2015). 
Se há uma valorização da África e não há correspondente contratação de modelos negras, há uma reprodução das características e feições negras em modelos brancas, como substituição. Podemos citar como exemplo os editoriais internacionais da Vogue Holanda (SORG, 2009) e da "Numéro" (WILSON, 2013), onde as modelos brancas foram pintadas de preto; no editorial da Riachuelo de 2015 onde utilizaram modelos brancas para representar a população do Marrocos - país africano e de sua maioria não-branca (RIACHUELO, 2015); dos desfiles de Renato Fraga no São Paulo Fashion Week, onde modelos (brancas e poucas negras) utilizaram palhas de aço para representar o cabelo crespo (SANCHES; SOUZA, 2013) e de Valentino, por apresentar a África com modelos brancas (BRUNET, 2015); e, do Baile de Carnaval 2016 da Vogue Brasil, com o tema Pop Africa, com diversas modelos e orientações voltadas para o branco se vestir à caráter (VOGUE, 2016).

Duas são as principais justificativas encontradas para tal fenômeno na versão dos criadores: 1) o mercado não oferece oferta de modelos negras, ainda que exista demanda; 2) a liberdade artística ou 'licença poética' do profissional seja designer, maquiador, estilista, e etc. Ainda que em ambos os casos tal prática não seja vista como ato discriminatório e racista pelos atores, os estudos sobre visibilidade do negro na mídia, e podendo ser aproveitado para este cenário, apontam que o preconceito de 'marca' (aparência) é associado a uma situação econômica e social desfavorável, culminando em pouca participação (BONADIO, 2012 apud SCHWARCZ, 2000). Mas, como participar se não é permitido 'competir'? Uma questão que precisa ser (re)pensada.

\section{Percurso metodológico}

Para atender ao objetivo proposto realizamos uma pesquisa qualitativa. Os dados analisados foram coletados na página oficial da Avon na rede social Facebook. Ressalta-se que tal corpus de análise já foi utilizado por Nascimento et al (2015) e se faz pertinente por ser um espaço onde os discursos naturalizados na sociedade se revelam.

Foram selecionados os comentários das pessoas que se manifestaram quanto à postagem da Avon no período 18/09/2015 a 13/01/2016. Embora o debate em torno da publicação na rede social tenha sido público e está acessível a qualquer pessoa, optamos por usar pseudônimos para dificultar a identificação pessoal daqueles cujo os textos selecionamos como fonte de dados para a pesquisa. Para a análise destes dados utilizamos a vertente da análise crítica do discurso (ACD) teorizada por Dijk (2012; 2013). Para esse autor, a análise crítica do discurso é "um tipo de investigação analítica discursiva que estuda principalmente o modo como o abuso de poder, a dominação e a desigualdade são representados, reproduzidos e combatidos por textos orais e escritos no contexto social e político" (DIJK, 2012, p. 113). Dijk (2012) defende que não é qualquer tipo de poder que interessa aos pesquisadores dos estudos críticos de discurso (ECD). O interesse está direcionado para o abuso de poder, fonte das formas de dominação que resultam na desigualdade e injustiça social, como o racismo. $\mathrm{O}$ abuso de poder se manifesta por práticas discursivas que objetivam o controle das ações e das mentes das pessoas. A ideia é que a influência sobre a mente do outro - por meio da difusão das ideologias defendidas pelos abusadores do poder - permite que o outro aja de acordo com os interesses de tais abusadores necessitando que eles empreendam poucos esforços para controlá-los.

Cabe ressaltar a observação de Dijk (2012) de que a análise crítica do discurso não é um método de análise de discurso. Ela é uma interação entre teorias, métodos de observação, descrição e análise, e suas aplicações. Os métodos empregados são diferentes e variam de acordo com as especificidades das pesquisas e dos interesses dos pesquisadores. $\mathrm{Na}$ presente pesquisa nos preocupamos majoritariamente com a análise semântica do corpus coletado. Para isso, realizamos a análise com base em três categorias distintas: a denúncia de racismo; a negação de racismo; e o contra-ataque à denúncia de racismo. $\mathrm{Na}$ primeira categoria analisamos os discursos que denunciam a prática de racismo na publicação da Avon. Na segunda, analisamos os discursos que negam esta prática como racista. $\mathrm{Na}$ última categoria, analisamos os discursos que revertem a lógica racista ao acusar os denunciantes como sendo os verdadeiros racistas.

Dos vários comentários registrados pelas pessoas que participaram do debate na publicação da Avon, dentro do período de recorte da pesquisa, selecionamos aqueles que propiciavam melhor colaboração para com o objetivo da pesquisa. Esses textos foram classificados de acordo com as categorias já mencionadas e receberam uma numeração crescente - entre colchetes no início de cada texto transcrito - à medida em que foram sendo apresentados para análise. 
O objetivo do uso dessa numeração é auxiliar na sua identificação e facilitar sua indicação no cruzamento entre os dados, se necessário. Cabe ressaltar que os trechos dos textos selecionados para análise foram apresentados assim como escritos por seus autores. Não efetuamos nenhuma correção gramatical ou de qualquer outro tipo, uma vez que as particularidades da forma como foram escritos também são passíveis de análise.

\section{0 que evidenciam os dados?}

\section{A denúncia de racismo}

[001] (...) O que a Avon fez chama-se blackface. Blackface é uma prática histórica, muito antiga. Onde as pessoas que faziam teatro eram todas brancas (começamos por aí.. Negros não tinham oportunidades de fazer teatro e expressarem-se artisticamente) e quando era necessário interpretar o papel de uma pessoa negra (geralmente acontecia para interpretar empregados domésticos ou personagens de zombaria) eles se pintavam de preto.. Ou seja, ao invés de chamar um cara negro pra interpretar o papel, pintava-se o cara branco de preto (que ficava ridículo e estimulava o humor e a zombaria contra o negro) para interpretar um papel de um personagem de submissão!! Percebe o quão tenso é isso? Por isso o Blackface É considerado racista. Ontem, hoje e sempre. E essa prática sobreviveu por muito tempo... Só que negro nenhum gosta de ser vítima de deboche, concorda? (Flávia)

[002] Blackface é racismo, não apropriação cultural. Racismo não é "desconforto", é crime (Jonas).

No fragmento discursivo [001] Flávia explica a que se refere o blackface e seu significado simbólico enquanto prática racista. Em sua fala Flávia assevera que o blackface é uma prática "muito antiga". Essa referência temporal é importante para categorizar o blackface como prática social naturalizada que por um longo período de tempo foi realizada sem ser questionada. Essa perspectiva é legitimada pela informação de Flávia de que essa prática teve início no teatro, em um período da história em que o negro era impedido de ocupar diversos espaços sociais, entre eles o de artista. A recusa social em permitir ao negro que ele represente no teatro sua própria raça é a primeira evidência de que o blackeface é uma prática racista. A segunda evidência - presente no discurso de Flávia - é de que essa representação do negro pelo branco "estimulava o humor e a zombaria contra o negro". O racismo é comumente encontrado na sociedade disfarçado em atividades humorísticas como em charges, anedotas, 'brincadeiras' entre amigos, na atribuição de apelidos, em programas de televisão, cinema e teatro, entre outros. Disfarçar o racismo em práticas humorísticas é uma das formas de reproduzir, naturalizar e silenciar o racismo. Uma vez reproduzido e naturalizado o racismo é pouco questionado pela sociedade e quando denunciado é normalmente negado, como será possível verificar na próxima seção de análise onde as estratégias de negação serão apresentadas. $\mathrm{Na}$ sentença "Por isso o Blackface É considerado racista", chama a atenção o fato de Flávia ter digitado o verbo "É" em letra maiúscula. Esse recurso evidencia que Flávia fez questão de enfatizar sua opinião em relação ao racismo presente na prática do blackeface. $\mathrm{Na}$ sequência de seu texto, o uso da expressão "ontem, hoje e sempre" é também um recurso linguístico empregado para reforçar sua opinião e deixar claro que esta opinião não está aberta para questionamentos. O blackeface como prática racista, para Flávia, é uma questão definitiva.

O texto de Flávia, parcialmente transcrito no fragmento discursivo [001], era particularmente direcionado a outra participante do fórum de discussão da rede social que não compreendia o black.face, relativo à publicação da Avon, como racista. Por essa razão Flávia decidiu dar um caráter didático ao seu texto e adotou como estratégia de persuasão a busca pela empatia de sua interlocutora, como se pode verificar no uso da frase interrogativa "Percebe o quão tenso é isso?", reforçada mais adiante por essa outra frase interrogativa "só que negro nenhum gosta de ser vítima de deboche, concorda?".

Jonas é também enfático ao classificar o blackface como prática racista, como se pode verificar no fragmento discursivo [002]. Em sua fala ele é incisivo em diferenciar racismo de apropriação cultural, conceito que discutiremos logo a seguir a partir da análise do fragmento discursivo [003]. Em sua fala "racismo não é "desconforto", é crime", Jonas busca enfatizar o racismo como prática criminal prevista na legislação. É importante observar que quando ele diz que racismo não é "desconforto", ele não quer dizer que a vítima de racismo não sofre desconforto com tal situação. A semântica do texto evidencia que ele defende que o racismo não pode ser reduzido apenas a um "desconforto", visto que é mais do que isto: é um crime. 
[003] Apropriação cultural é quando você se apropria de algo de uma cultura que não te pertence. Vitiligo é uma doença e o que vocês deveriam ter feito para provar a beleza da tal maquiagem seria usar uma modelo que REALMENTE tivesse a doença, e não acharem inovador uma garota branca cheia de base fora do seu tom de pele espalhada pelo corpo como forma de representar alguém com a doença (Paula).

Paula apresenta em seu texto transcrito em [003] um conceito para a apropriação cultural. A apropriação cultural é retratada de forma depreciativa, uma vez que essa apropriação de algo que não lhe pertence remete interdiscursivamente ao conceito legal de furto. O sentido que Paula atribui à apropriação cultural não pode ser confundido, portanto, com a possibilidade de um indivíduo ou grupo social absorver aspectos de uma cultura pertencente a outro grupo social. $\mathrm{Na}$ pesquisa observamos que outros debatedores da publicação da Avon na rede social adotam o conceito de apropriação cultural de forma semelhante a Paula. Não identificamos nenhuma dissonância em relação a este conceito, o que nos evidencia que a interpretação apresentada é majoritária entre os denunciadores de racismo cujo os textos foram analisados nesta pesquisa. Isso nos leva de volta ao fragmento discursivo [002] onde Jonas diz que blackface não é apropriação cultural, mas apenas racismo. Se tomarmos como correto esse conceito de apropriação cultural, a assertiva de Jonas se mostra incorreta, uma vez que o blackeface, além de uma prática racista, é também uma apropriação cultural utilizada para reproduzir o racismo socialmente. Por isso Paula não cita racismo em seu texto. Sua reprovação à publicação da Avon é tratada como apropriação cultural e sua crítica mais focada na pessoa com vitiligo, como se percebe em: "vitiligo é uma doença e o que vocês deveriam ter feito para provar a beleza da tal maquiagem seria usar uma modelo que REALMENTE tivesse a doença, e não acharem inovador uma garota branca cheia de base fora do seu tom de pele espalhada pelo corpo como forma de representar alguém com a doença".

[004] Existe uma coisa chamada minoria. Existe também outra coisa chama protagonismo. Essas duas coisas estão intimamente ligadas e são muito necessárias pra desconstruir todo e qualquer tipo de preconceito existente na nossa sociedade. LGBTfobia (homofobia, transfobia, bifobia). Racismo. Machismo. Esses são exemplos de preconceitos encrustados na cabeça das pessoas, que faz com que todos nós não nos coloquemos no lugar de quem sofre/ sofreu com eles a vida toda. O que acontece quando não nos colocamos no lugar de quem sofre o preconceito? Nós achamos que temos o direito de falar o que é certo, o que é errado, o que é melhor e o que é pior pra resolver a polêmica da pessoa que tem o preconceito em questão (Flávia).

No texto reproduzido em [004] Flávia continua sua explanação fundamentando sua perspectiva de que o blackeface é uma prática racista. Flávia ainda está se dirigindo, particularmente, à outra debatedora a que já nos referimos anteriormente. Flávia estabelece em seu discurso a ideia de que a conscientização a respeito dos conceitos de 'minoria' e 'protagonismo' estão intimamente ligados e possuem importância fundamental para a 'desconstrução' dos diversos tipos de preconceitos existentes na sociedade. Os textos de Flávia dialogam interdiscursivamente com outros discursos que objetivam o combate ao racismo e demais formas de preconceito estabelecidos na sociedade. Como já dito anteriormente, Dijk (2012) defende a perspectiva de que o racismo - e isso pode ser aplicado aos demais preconceitos - não são naturais e sim construídos socialmente. $\mathrm{O}$ texto de Flávia evidencia que ela corrobora desta perspectiva já que menciona a possibilidade e a necessidade dos diversos preconceitos serem "desconstruídos": "Essas duas coisas estão intimamente ligadas e são muito necessárias pra desconstruir todo e qualquer tipo de preconceito existente na nossa sociedade" (Flávia). Há nesta sentença, portanto, o implícito pressuposto de que se os preconceitos precisam ser desconstruídos e somente se pode desconstruir o que foi previamente construído. Os textos de Flávia evidenciam que ela está envolvida com a ideologia de combate ao racismo e demais preconceitos e estuda ou se informa sobre o tema, já que traz para o seu texto conceitos e conteúdos pertinentes a esses outros discursos. Outro trecho que colabora com a perspectiva de que os preconceitos são construídos socialmente pode ser observado no uso da expressão "preconceitos encrustados na cabeça das pessoas". $O$ verbo encrustar dá o sentido semântico de que os preconceitos foram embutidos na cabeça das pessoas. Por isso a autora adverte que quando não praticamos a empatia, não nos colocamos no lugar do outro daquele que sofre os preconceitos - não temos a real compreensão do fenômeno social e, portanto, não estamos habilitados a opinar sobre ele. 
A análise semântica da sentença: "Esses são exemplos de preconceitos encrustados na cabeça das pessoas, que faz com que todos nós não nos coloquemos no lugar de quem sofre/sofreu com eles a vida toda" (Flávia), evidencia que está subentendida a perspectiva de naturalização do racismo e demais preconceitos. Isto porque a naturalização torna a percepção das práticas racistas, homofóbicas, sexistas, etc., corriqueiras, comuns, aceitáveis no cotidiano social. A naturalização suaviza, esconde, dificulta a conscientização sobre a real gravidade de tais práticas, em especial, por aqueles que a praticam ou a assistem com indiferença.

[005] Agora, o que algumas pessoas estão tentando fazer aqui, é justamente mostrar pra Avon que o que ela fez foi algo muito feio, impróprio e racista sim. Ela tá fazendo uso de uma prática antiga que acaba perpetuando na cabeça das pessoas (mesmo que SEM QUERER) a ideia de que zombar de negro pode. De que negro é facilmente substituível por um branco. Ou seja. Ela ajuda a perpetuar o racismo. Mesmo que seja sem querer, precisa ser problematizado, precisa ser dito, as pessoas, PRINCIPALMENTE as negras precisam chegar e dizer que isso não tá certo, que não foi legal e que foi ofensivo pra elas (Flávia).

No fragmento discursivo [005] Flávia é explicita ao defender que a Avon - possivelmente sem se dar conta disto - realizou uma prática racista com o blackface em seu concurso de maquiagem. Na sentença "mesmo que SEM QUERER", Flávia usa o recurso de escrever em caixa alta a expressão 'sem querer'. Podemos interpretar a intenção de seu ato de duas formas distintas, antagônicas entre si. A primeira interpretação é de que Flávia quis enfatizar a possibilidade da Avon não ter tido qualquer intencionalidade condenável na publicação do blackface. Na segunda, em um sentido oposto, pode-se interpretar que Flávia tende a acreditar que havia uma intencionalidade racista na prática da Avon. O Texto não nos dá elementos concretos para definirmos a posição de Flávia neste item. O texto [005] evidencia a perspectiva de Flávia de que o blackface perpetua o racismo ao expor a imagem do negro a situações de chacota e humilhação, bem como ao colocá-lo na posição de alguém que é facilmente substituível pela pessoa branca, naturalizando o preconceito contra ele.
$\mathrm{Na}$ sentença "PRINCIPALMENTE as negras precisam chegar e dizer que isso não tá certo, que não foi legal e que foi ofensivo pra elas", Flávia dá um ultimato às mulheres negras. Está implícito no texto o conceito de protagonismo. No que diz respeito à publicação da Avon, o ultimato de Flávia não é direcionado ao homem negro possivelmente pelo fato do blackeface ter envolvido uma modelo branca, sendo maquiada para se parecer com uma modelo negra, e ter sido promovido por uma empresa multinacional de cosméticos voltada ao público feminino. Portanto, os dados evidenciam que na percepção de Flávia este blackface envolveu o universo feminino e compete a elas o protagonismo de denunciar e lutar contra esta prática racista. O uso do léxico 'principalmente' em caixa alta evidencia a importância que Flávia confere ao protagonismo da mulher negra neste caso.

O protagonismo volta a ser tema em outro fragmento discursivo de Flávia, como se pode verificar em [006].

[006] Por fim, o roubo do protagonismo. Que é algo que inclusive eu estou fazendo. Por quê? Porque quem deveria estar aqui falando sobre tudo isso, sobre Blackface, sobre a história dos negros, sobre como eles se sentem são ELES. Porque ELES é quem passam por isso TODOS OS DIAS. Não eu. São eles que enfrentam as piadas infames com "neguinho do cabelo duro", que são abordados pela polícia somente por serem negros, que não estão nas escolas particulares nem nas universidades, que são deixados de lado ou como segunda opção na hora de escolher um bom emprego... Enfim, que são discriminados todos os dias (Flávia).

Ao falar sobre roubo de protagonismo Flávia afirma que ela própria está cometendo tal roubo. Isto porque "quem deveria estar aqui falando sobre tudo isso, sobre Blackface, sobre a história dos negros, sobre como eles se sentem são ELES" (Flávia). Ao se reportar aos negros como 'eles', e enfatizar isto com o uso da caixa alta, verifica-se o implícito pressuposto de que Flávia não pertence a este grupo social. Embora se manifeste contra o racismo, Flávia não se sente com legitimidade para falar do tema - por isso o roubo do protagonismo - pois quem deveria denunciar e lutar contra o racismo são os negros, "porque ELES é quem passam por isso TODOS OS DIAS” (Flávia). Nesta última citação verificamos que Flávia novamente se utiliza da caixa alta para destacar os léxicos 'eles' e 'todos os dias'. Novamente se busca enfatizar a necessidade de protagonismo dos negros que são 
vítimas do racismo cotidianamente, pelas piadas e 'brincadeiras' de mau gosto com destaque, no texto de Flávia, para aquelas direcionadas para os seus cabelos crespos. Flávia ainda menciona outros exemplos de agressões racistas sofridas pelos negros na sociedade, como pelas constantes abordagens policiais motivadas apenas pela cor da pele; na ausência de negros - em números representativos - nas escolas particulares e nas universidades públicas. Fica subentendido nas colocações de Flávia sua percepção e reconhecimento de que as práticas racistas restringem as possibilidades de desenvolvimento socioeconômico dos negros e os colocam em um lugar secundário - marginal - da sociedade. Daí a importância do negro buscar ser protagonista no combate ao racismo.

[007] Pintar a pessoa negra de branco tbm é racismo. Deixa eu explicar (de novo) Não é pra pintar preto de branco, nem branco de preto. Sao pessoas distintas, não tem que colocar o branco pra fazer papel de negro, nem tem que embranquecer o negro pra ele ser “menos" negro. É uma questão de identidade e representatividade (Tatiana).

No fragmento discursivo [007] temos Tatiana como outra personagem que denuncia o racismo. Neste texto, Tatiana está se dirigindo diretamente a outra debatedora que não reconhece a prática do blackface como racista e teria defendido que seria racismo apenas se uma modelo negra tivesse sido maquiada para se parecer branca. Para Tatiana, no que se refere às práticas racistas, não se deve 'pintar' negros de branco e tampouco brancos de negros. No entanto, há uma diferença significativa entre essas duas possibilidades. 'Pintar' o branco de negro caracteriza a prática do blackface cujo teor racista já foi anteriormente discutido nesta pesquisa. 'Pintar' o negro de branco, por sua vez, tem um significado diferente conforme evidencia o texto de Tatiana. Essa prática não caracteriza racismo contra a pessoa branca, mas sim contra o próprio negro, uma vez que isso representaria um 'embranquecimento' do negro para ele ser 'menos' negro. Há que se respeitar, na opinião de Tatiana, a identidade e a representatividade do negro. Este respeito à identidade e representatividade está interdiscursivamente relacionada à apropriação cultural - já discutida anteriormente - que se faz, indevidamente, da cultura negra.

[008] "Uuui... só negro entende racismo..." SIM Branco não sofre racismo (Cleide).

[009] Brancos falando o que é ou não racismo gatinha não é válido ... Quem define o que é racismo, o que é apropriação cultural são os negros. Negro sofre racismo, não venham tentar silenciar .. Se vc é branca, não tem que dar pitaco nesse assunto ... (Emília)

Nos textos [008] e [009] Cleide e Emília, respectivamente, defendem que apenas os negros, enquanto grupo social vítima de racismo, tem legitimidade para definir o que é ou não racismo. Os textos são reações a pessoas brancas que se manifestaram dizendo que o blackface publicado pela Avon não é uma prática racista. A pessoa branca, tanto para Cleide como para Emília, não possui legitimidade para definir o que é ou não racismo uma vez que fazem parte de um grupo social que não sofre racismo. Portanto, não podem dar "pitaco neste assunto" (Emília). As autoras silenciam em seus respectivos discursos que além de não sofrerem racismo as pessoas brancas são aquelas que majoritariamente promovem e perpetuam o racismo contra os negros. Os brancos compõem a 'elite majoritária' que preenche os melhores espaços sociais e tem acesso às melhores oportunidades, ocupando os lugares de poder que possibilitam a instauração e reprodução do racismo em suas práticas de abuso do poder, como defendido por Dijk (2012).

\section{A negação do racismo}

Dijk (2012) defende que as normas e valores gerais contemporâneos, até mesmo a própria lei, proíbem as práticas de preconceito e discriminação étnica. No Brasil o racismo é tipificado como crime e outras formas de discriminação, como a religiosa e a de procedência nacional, também são condenadas pela lei. Em vista disto, os praticantes de racismo acabam por evitar formas explícitas de manifestarem suas ideologias discriminatórias e buscam formas mais sutis de o fazerem. Uma das formas de manifestar racismo se dá pela negação de sua existência.

As negações do racismo e formas semelhantes de autoapresentação positiva apresentam tanto uma dimensão individual como social. A 
maioria dos falantes brancos não somente se sentem ofendidos por serem individualmente percebidos como racistas, mas também, e de forma mais importante, tais estratégias podem ao mesmo tempo visar a defesa do grupo como um todo: "Não somos racistas"; "Não somos uma sociedade racista" (DIJK, 2012, p. 158).

Para o referido autor, as pessoas com comportamento racista se preocupam com uma avaliação geral negativa de sua personalidade, uma vez que ser categorizado como racista ou intolerante pressupõe uma característica pessoal, duradoura de sua personalidade (DIJK, 2012). A negação seria, portanto, uma estratégia de autopreservação da própria imagem perante a sociedade. Segundo o autor, os tipos mais comuns de negação são: negação do ato; negação do controle (sobre o ato); negação da intenção e negação do propósito (DIJK, 2012). Neste tópico iremos analisar os comentários que evidenciam a prática da negação.

\begin{abstract}
[010] Não vi nada de agressivo ou desrespeitoso nessa maquiagem. O povo tá tão nessa onda de politicamente correto, que tá enchendo o saco! Não entendem arte... Não entendem conceito. Destroem qualquer liberdade artística... afffffffffffffffff $\mathrm{O}$ povo entrou numa noia tão grande que a Avon tirou do ar o editorial e ainda foi a público perdi desculpas. Cara... pedir desculpas pelo quê??? Por fazer arte??? Por saber lidar com as diferenças com arte??? (Regina).
\end{abstract}

[011] Lamentavelmente as pessoas se acostumaram com esse conceito de "fast" e não param mais pra analisar com cuidado e atenção mais nada! Se não vier "embrulhado pra viagem" as pessoas ou ignoram ou fazem polêmica, com algo que foi feito justamente para fazer a gente pensar... analisar... observar nossos próprios preconceitos e a avalanche de padrões que somos constantemente expostos e bombardeados. A arte, assim como a literatura e outras expressões culturais, tem essa função; a de fazer a gente repensar... analisar... Não é só o belo! Existe todo um conceito por trás. A gente só precisa dedicar um pouco de tempo, carinho e esforço para isso (Vanessa).

[012] A avon usou da arte pra fazer a gente pensar! A arte e a moda tem um casamento antigo, construtivo e saudável (Alice).

No fragmento discursivo [010] Regina apresenta sua perspectiva de que o blackface publicado pela Avon não constitui uma prática racista, e sim uma expressão artística. A primeira frase - "Não vi nada de agressivo ou desrespeitoso nessa maquiagem" - evidencia a presença da negação do ato, visto que a autora alega não ter percebido qualquer prática racista na publicação. O uso do léxico 'maquiagem' para nomear o ato, em lugar de 'blackface' como o fizeram as denunciantes de racismo no tópico anterior, reforça o posicionamento de Regina. A negação do ato persiste na frase seguinte - "O povo tá tão nessa onda de politicamente correto, que tá enchendo o saco!" - visto que a frase tenta desqualificar a denúncia tomando-a como sem fundamento, fruto de uma postura exagerada por aqueles que aderiram à 'onda do politicamente correto'. Como a ideologia e as práticas racistas foram naturalizadas em nossa sociedade por um longo período de tempo, é possível inferir que o discurso de Regina é uma evidência da dificuldade que muitas pessoas tem em reconhecer tais ideologias e práticas como sendo de desvio ético/moral, de não se reconhecerem como racistas (para os casos em que isso é pertinente - aqui não fazemos referências diretas a Regina visto que não há esta evidência nos dados) e de não reconhecer a legitimidade das denúncias daqueles que as identificam. Por isso, o 'empoderamento' dos negros e das demais vítimas de discriminação e suas atitudes de 'protagonismo' são vistas como um exagero na exigência de uma conduta correta.

O uso da expressão 'politicamente correto' é utilizado por Regina de forma depreciativa. Neste sentido, ser politicamente correto pode ser associado à necessidade das pessoas terem de controlar seus discursos e atos afim de não deixar transparecer, de não tornar explícito, os preconceitos sociais que carregam no íntimo. Como disse Dijk (2012), as pessoas se preocupam em não serem rotuladas de racistas. Há que se preservar a boa imagem, mesmo que ela não corresponda com a realidade.

Regina classifica o blackface publicado pela Avon como arte e qualifica aqueles que denunciaram a prática como racista como pessoas que não entendem de arte e dos conceitos atrelados às obras artísticas. Vanessa, no fragmento discursivo [011], e Alice, no fragmento discursivo [012], também consideram que se trata de um exercício artístico, sem nenhuma conotação racista. Classificar o ato da Avon como arte é uma negação do tipo 'negação de intenção'. Neste tipo de negação defende-se que ocorreu um erro de interpretação por parte daqueles que viram racismo onde ele não existe. No caso em questão, os denunciantes interpretaram racismo onde só existia arte, como se pode verificar na fala de Alice em [012]. 
Em [011], o texto de Vanessa evidencia que ela qualifica os denunciantes, representados no texto como "as pessoas", como sujeitos que não param para refletir e analisar corretamente os acontecimentos e acabam por tirar conclusões precipitadas. Vanessa se utiliza do léxico "fast" da língua inglesa para defender seu argumento de que as pessoas "não param mais pra analisar com cuidado e atenção mais nada". Está subentendido no texto que a 'atividade artística' publicada pela Avon convidava as pessoas a observar os próprios preconceitos e a "avalanche de padrões que somos constantemente expostos e bombardeados". Vanessa evidencia não ter percebido que empresas multinacionais como a Avon, que atuam no setor de moda e cosméticos, criam e impõem padrões de beleza para a sociedade, utilizando de seus ricos recursos para nos 'bombardear' discursivamente com suas peças de marketing influenciando nossa percepção sobre o que é belo e o que não é. É de conhecimento comum que o padrão de beleza hegemônico é a da pessoa branca, de olhos claros, alta, magra, de cabelos lisos e preferencialmente claros. Há pouco ou nenhum espaço para o reconhecimento da beleza negra. A denúncia de racismo na publicação da Avon é também uma forma de protesto contra esse pouco ou nenhum espaço para a beleza negra.

[013] A Avon era uma empresa de maquiagem
e promoveu um concurso de MAQUIAGEM.
Por isso, uma modelo branca foi pintada de
negra com vitiligo, pra representar o poder
de transformacao da maquiagem! Nao ha
racismo nisso, a maquiadora usou esse projeto
pra celebrar a diversidade! Leiam a proposta
do concurso, o projeto da vencedora... O
título é "somos todos um"... Informem-se
mais (Pedro).

No discurso de Pedro em [013] evidencia-se, também, a negação de intenção, uma vez que, segundo Pedro, a intenção da autora das fotos era 'celebrar a diversidade'. Não se pode 'celebrar a diversidade' com uma prática racista que existe desde o século XIX. O blackeface está simbolicamente investido de racismo e somente não é reconhecido como tal porque as elites sociais - que possuem o poder de propagar sua cultura e ideologia pelas mídias, pelo sistema de ensino, pelo sistema político, pelas organizações, pela arte, etc. - negam que práticas como esta são racistas. A título de exemplo, tomemos outro símbolo. A suástica e a tradicional saudação nazista somente são reconhecidas como símbolos racistas porque as elites mundiais das nações vencedoras da II grande guerra estabeleceram esta ideia e a reproduziram na sociedade mundial, de forma que, ainda hoje, passadas algumas décadas após o término da guerra, não fazemos referência a esses símbolos senão para criticar a ideologia discriminatória que representam. No entanto, práticas como o blackface ainda não são reconhecidas como discriminatórias por uma parcela significativa da sociedade.

Ao ser criticada em sua página na rede social após ter publicado as fotos do blackface, a Avon retirou a publicação e postou um pedido de desculpas para aqueles que se sentiram ofendidos, sendo os comentários desta segunda publicação nossa fonte de dados para esta pesquisa. Apesar da Avon ter reconhecido publicamente seu erro e buscado se retratar, Regina não concorda com a retratação, como se verifica no fragmento discursivo [010] - "Avon tirou do ar o editorial e ainda foi a público perdi desculpas. Cara... pedir desculpas pelo quê??? Por fazer arte??? Por saber lidar com as diferenças com arte???” (Regina). Persiste a negação da intenção ao qualificar o blackface como arte e negar-lhe a condição de prática racista.

[014] Qualqr coisa hj em dia eh racismo, q sacooo.. Entao se eu chama um amigo negro de negao vou estar sendo racista, ? Q gente sem noção aff (Paula).

A análise do discurso de Paula no texto [014] nos evidencia a presença de outro tipo de negação, a negação do propósito. O uso do léxico 'amigo' no exemplo apresentado por ela tem como implícito pressuposto que chamar o "amigo negro" de negão é manifestação de carinho e amizade e não de racismo. Paula ainda relativiza as denúncias de racismo ao dizer que qualquer 'coisa' contemporaneamente é taxado de racismo. O discurso de Paula evidencia os efeitos da naturalização do racismo que faz com que seja difícil às pessoas que não sofrem esse tipo de violência as percebam, bem como a aqueles que a praticam se reconhecerem racistas. Talvez por isso ela pratica uma inversão ao qualificar como sem noção os outros que denunciam sua ideologia racista. As práticas discursivas de inversão serão melhor analisadas no próximo tópico. 


\section{O contra-ataque à denúncia de racismo}

Não raro, as negações de racismo vem acompanhadas de um contra-ataque à aqueles que o denunciam, a quem Dijk (2012) chama de antirracistas. Segundo este autor, os contra-ataques são movimentos estratégicos que objetivam desconstruir o discurso antirracista. Três estratégias se destacam, sendo elas: a pressuposição da 'verdade', onde as práticas racistas são

negadas como tal e defendidas como sendo expositoras de uma 'verdade' social que não se quer enfrentar; o movimento estratégico da reversão, que consiste em qualificar como sendo os verdadeiros racistas aqueles que denunciam as práticas racistas; a inversão de acusações, que objetiva estabelecer como verdadeiras vítimas aqueles que são acusados de racismo (DIJK, 2012).

[015] A maldade está nos olhos de quem vê. (Carolina)

[016] A maldade.está nos olhos de quem vê. Eu sou negra. (Carolina)

[017] Eu sou negra e naum vi como racismo , as vezes as pessoas veem demais... (Marcela)

A análise semântica do texto [015] de Carolina evidencia que está implícita a perspectiva de que o racismo está nos olhos daquele que o enxerga, e não na prática do racismo em si. No texto seguinte, em [016], objetivando legitimar seu ponto de vista, Carolina repete a frase - possivelmente por erro de digitação há um ponto final entre as palavras 'maldade' e 'está' - acrescentando a informação de que é negra. Ao se autodeclarar negra Carolina pretende se apresentar como alguém habilitada a avaliar a prática da Avon como racista ou não, uma vez que é o grupo social vítima de discriminação que tem legitimidade para tratar do tema, como foi defendido por Flávia em [004], Cleide em [008] e Emília em [009]. Ao utilizar o léxico 'maldade' Carolina expande sua perspectiva para outras violências além do racismo. A palavra 'maldade', portanto, pode ser substituída tanto por racismo quanto por estupro, roubo, assédio, assassinato ou qualquer outra que possa ser adjetivada como uma 'maldade'. Logo, sua afirmação poderia ser reescrita assim: 'o estupro está nos olhos de quem vê'; 'o assédio está nos olhos de que vê'; 'a violência está nos olhos de quem vê', argumento que fere qualquer princípio lógico pautado no bom senso. Está implícita na afirmação de Carolina e explícita na de Marcela [017] a negação do ato, justificado pelo fato de não terem observado qualquer prática racista no blackface publicado pela Avon. Marcela também objetiva legitimar seu ponto de vista ao se autodeclarar negra se não viu é porque não existiu, como se toda a pessoa negra estivesse capacitada para reconhecer o racismo. No entanto, como já argumentado nos tópicos anteriores, as práticas racistas estão naturalizadas na sociedade e nem sempre são facilmente identificadas. As práticas racistas são muitas vezes sutis, o que dificulta que sejam reconhecidas como tal.

A defesa de que "a maldade está nos olhos de quem vê" (Carolina) se caracteriza como uma pressuposição da 'verdade', que nega o racismo justificando que são as pessoas que, as vezes, veem demais, como defendeu Marcela em [017].

[018] Uuui..só negro entende racismo...vc está sendo racista então..ja vi muito racismo e siu completamente contra..e mesmo sendo branca(meu pai é negro) entro em qualquer briga por racismo...agora seje menas com essa de "só negro pode dizer se é racismo ou nao" eu não sou cega...tbm sei ver o rascismo. (Joseane)

No fragmento discurso [018] o discurso de Joseane nos apresenta um exemplo de reversão. Joseane rebate $\mathrm{o}$ argumento de que somente o negro tem legitimidade para discutir o racismo defendendo que esse tipo de raciocínio configura, também, uma prática racista para com aqueles que não são negros e se sentem capazes de o fazê-lo. Joseane se autodeclara branca mas buscou se legitimar no debate ao se declarar como filha de um negro. É importante observar que a discussão em torno do ser ou não negro se limita à cor da pele. $\mathrm{O}$ discurso silencia outros fatores que envolvem a raça como as relações sociais e de parentesco, a genética - que vai além da cor da pele - e os aspectos culturais, entre outros, que juntos podem melhor definir nossos vínculos étnico-raciais. Ao rebater a legitimidade exclusiva do negro para avaliar as práticas racistas Joseane defende que outras pessoas não negras estão capacitadas para identificálo, como evidencia a sentença: "eu não sou cega... tbm sei ver o racismo" (Joseane). É evidente que as pessoas não negras podem perceber práticas racistas contra os negros ou pessoas de outras raças. No entanto, quem não vivencia cotidianamente a violência 
racista como vítima terá sempre que desenvolver uma sensibilidade para reconhecê-la. Isto ocorre principalmente porque a naturalização do racismo obscurece nossa percepção - e isto é válido para pessoas negras também, já que a pesquisa evidenciou que pessoas que se autodeclararam negras também demonstraram dificuldades em identificar o racismo em algumas práticas sociais - não apenas no que se refere a perceber determinadas práticas como racistas como a se perceber como alguém que também pode estar empreendendo práticas racistas.

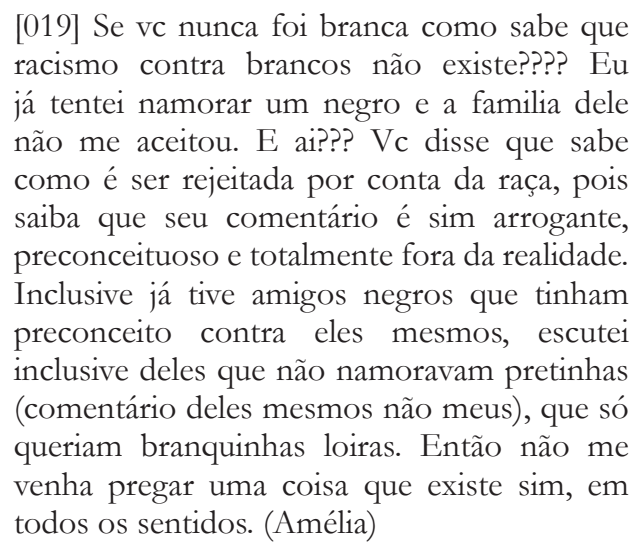

O texto de Amélia em [019] caracteriza-se como um exemplo de inversão de acusações. Amélia inicia seu discurso questionando uma interlocutora negra. Em seu texto, Amélia tenta justificar que existe também racismo contra a pessoa branca. O texto de Amélia relaciona-se interdiscursivamente com o de Flávia em [004]. Cabe lembrar que, assim como disseram Johnson e Bankfead (2013), bem como Souza (1983), a estética branca é hegemônica e ocupa uma posição de poder na hierarquia social, que lhe permite definir e legitimar o que deve ser considerado belo e o que deve ser considerado feio. Portanto, não se pode incluir a raça branca no conceito de minoria e, embora pessoas brancas também possam estar sujeitas a situações específicas e eventuais de discriminação, não podem ser declaradas como vítimas de racismo. Amélia busca inverter a lógica do racismo e vitimizar o grupo social que ao longo de muitos séculos tem promovido o abuso de poder contra outros grupos, escravizando, segregando, humilhando, ridicularizando, assassinando, entre tantas outras práticas nefastas. Amélia pode não ter percebido que quando seus amigos negros diziam que não queriam namorar 'pretinhas' e sim 'brancas de cabelos loiros', isto se dá justamente pela hierarquia racial, social e de valores que se estabeleceu entre brancos e negros. Todos os instrumentos de poder a serviço da elite social - que é branca - como o sistema de ensino, a mídia, a indústria da moda, etc., reproduz a estética, o modo de vida, a cultura do 'homem' branco como sendo aquela a que se deve admirar e assumir. Não é sem fundamento que tais amigos negros supervalorizaram a beleza branca, que se tornou um padrão estético mundial, e passaram a desejar mulheres que atendiam a este padrão, desvalorizando ou não reconhecendo a beleza da mulher negra. As práticas racistas sabem também ser sedutoras e não raro conseguem ludibriar e angariar a adesão daqueles que mais a deveriam combater.

\section{Considerações finais}

Esta pesquisa teve por objetivo analisar os diferentes posicionamentos discursivos manifestados por usuários de redes sociais sobre práticas denunciadas como racistas. Para atender a este objetivo, realizou-se uma pesquisa de natureza qualitativa que analisou os discursos presentes em comentários realizados por usuários da rede social Facebook, em uma postagem da empresa de cosméticos Avon relacionada a uma prática de blackface. Com base nos dados encontrados foi possível classificar os discursos em três diferentes categorias, sendo elas: a denúncia de racismo; a negação de racismo; e o contra-ataque à denúncia de racismo.

$\mathrm{Na}$ primeira categoria encontram-se os discursos que denunciam o blackface como uma prática racista, visto que impede a representatividade e o protagonismo negro, bem como por estar historicamente associada a uma cultura racista que se utilizava, e ainda se utiliza, do humor e da zombaria para depreciar a pessoa negra. Na segunda, foram agrupados e analisados os discursos que negaram a prática do blackface, publicado pela Avon, como prática racista e a designaram como arte e expressão artística. $\mathrm{Na}$ terceira e última categoria foram selecionados e analisados os discursos de contra-ataque às denúncias de racismo, que objetivavam inverter a lógica racista posicionando os denunciantes como os verdadeiros racistas.

Através da análise crítica do discurso teorizada por Dijk (2012, 2013) tornou-se possível compreender as relações de poder que permeiam a sociedade (instituições como a Avon e pessoas como os usuários da rede social analisada) no estabelecimento de relações de dominação, marcado por uma estética branca hegemônica, em consonância com as observações 
de Sansone (1996), que produz desigualdades, delimitando quais espaços o negro pode ou não ocupar, como os do fashionismo e da beleza.

A análise crítica do discurso se mostrou adequada e eficiente na pesquisa, visto que permitiram extrair dos diferentes discursos os elementos linguísticos necessários para se aprofundar na análise dos dados. Tal como defendido por Dijk (2012), a pesquisa evidenciou que a negação ao racismo é uma forma de autopreservação da imagem positiva dos agentes sociais, visto que ninguém quer ser percebido como racista. Associada à negação, o contra-ataque à denúncia de racismo foi evidenciado como um movimento estratégico de reversão que buscou qualificar os próprios negros, bem como os não negros que denunciaram o blackface como prática racista, como os verdadeiros algozes deste fato social.

A pesquisa evidenciou que as práticas racistas continuam disseminadas na sociedade. Mas, seu reconhecimento ainda é dificultado por sua naturalização e silenciamento, como se vivêssemos em uma democracia racial. Embora os negros constituam o principal grupo social brasileiro vítima de racismo, nem todas as pessoas autodeclaradas negras reconheceram o blackface como prática racista, exemplificando a dinâmica das relações de poder e como a difusão das ideologias dominantes atingem a mente das pessoas de forma simbólica, tornando natural a reprodução das práticas sociais capazes de manter o status quo. Por outro lado, pessoas autodeclaradas 'brancas' foram capazes de perceber no blackeface uma prática reprodutora da cultura racista que se mantem ativa em nossa sociedade. A pesquisa evidenciou, por tanto, que a percepção do blackface como arte ou prática racista não está diretamente relacionada à cor da pele de quem a analisa, mas à sua percepção cognitiva embasada na sua cultura, experiência de vida, capacidade crítica, conhecimento histórico, entre outros fatores. Adicionalmente, destaca-se que a arte e as expressões artísticas não estão isentas das relações de poder e dos processos de dominação e por isso não são argumentos válidos para negar a existência do racismo.

A pesquisa também evidenciou que o racismo é pouco debatido e estudado na sociedade, o que contribui para a sua perpetuação. Notou-se que um número significativo de pessoas que postaram comentários na publicação analisada estavam desinformadas em relação à temática do racismo, da história, da cultura e da escravização dos povos negros trazidos ao Brasil. A desinformação não permite que o debate em torno deste importante problema social leve à conscientização da sociedade e à necessária mudança social que corrija este desvio. Em relação à esta questão, a pesquisa demonstrou a necessidade das pessoas negras, ainda mais do que as pessoas brancas, por serem as principais vítimas do racismo na sociedade brasileira, se instruírem em relação às relações de poder estabelecidas, ao abuso de poder, às formas de dominação, que promovem a desigualdade e a injustiça social (DIJK, 2012; 2013), empoderandose e assumindo o protagonismo necessário para combaterem o racismo.

Não obstante, acredita-se em alternativas de resistência para o enfrentamento dos discursos dominadores. Um exemplo recente remete ao desfile da LAB na 42a edição da São Paulo Fashion Week de 2016 onde a empresa Laboratório Fantasma (Lab), dos rappers Emicida e Evandro Fióti, apresentou uma coleção inspirada na lenda de Yasuke, negro de Moçambique que teria se tornado samurai no Japão do século XVI (O GLOBO, 2016) com $90 \%$ do seu casting com modelos negros. Estes protagonismos em espaços típicos de elites simbólicas (DIJK, 2008) poderiam contribuem para alterar a representação social dos negros nos espaços organizacionais e sociais criando identidades positivas.

O presente estudo contribui com a área de Estudos Organizacionais, inicialmente, por corroborar com um esforço de pesquisadores brasileiros (LAGE; SOUZA, 2016; NASCIMENTO et al., 2015; TEIXEIRA, 2015; ROSA, 2014; CONCEIÇÃO, 2009) em problematizar as relações raciais no campo dos estudos organizacionais, bem como, especificadamente, ao possibilitar que se coloque em discussão a falta de espaço e reconhecimento que as organizações que atuam no mundo fashionista e da beleza oferecem à mulher negra, seja como profissional - pela ausência de modelos negras em números representativos -, seja como clientes, ao continuar reproduzindo a estética 'branca' como padrão hegemônico a ser admirado e perseguido. A ampliação da discussão em torno da temática do racismo é imprescindível para que a sociedade possa promover a extinção desta forma de desigualdade e injustiça social e seja capaz de abrir espaço para que a beleza de mulheres de 'outras cores' possam ser valorizadas. 


\section{Referências bibliográficas}

BONADIO, M. C. As modelos negras na publicidade de moda no Brasil dos anos 1960. Visualidades, v.

7, n. 9, p. 68-97, 2012.

BORGES, S. ONG pressiona por cotas para modelos negros em feira de SP. O Globo, 16 de outubro de 2015. Disponível em: <http://oglobo. globo.com/sociedade/ong-pressiona-por-cotas-paramodelos-negros-em-feira-de-sp-17792599>. Acesso em: 20 de janeiro de 2016.

BRAGA, A. História da beleza negra no Brasil: discursos, corpos e práticas. São Carlos: EdUFSCar, 2015. 273 p.

BRUNET, N. Valentino desfila coleção inspirada na África, mas "esquece" dos negros. The Brontes, 6 de outubro de 2015. Disponível em: <http:// thebrontes.co/2015/10/valentino-desfila-colecaoinspirada-na-africa-mas-esquece-dos-negros $/>$. Acesso em: 20 de janeiro de 2016.

CHAPMAN, Yolanda Michele. "I am Not my Hair! Or am I?": Black Women's Transformative Experience in their Self Perceptions of Abroad and at Home. Georgia State University, 2007. Disponível em: < http://scholarworks.gsu.edu/anthro_ theses/23>. Acesso em: 7 set. 2015.

CONCEIÇÃO, E. B. DA. A Negação da Raça nos Estudos Organizacionais. In: EnANPAD, 33., 2009, São Paulo. Anais... São Paulo: ANPAD, 2009. p-116.

DIJK, T. A. Cognição, discurso e interação. $7^{\mathrm{a}}$ ed. São Paulo: Contexto, 2013.

DIJK, T. A. Discurso e poder. $2^{a}$ ed. São Paulo: Contexto, 2012.

DIJK, T. A. VAN. Racismo e discurso na América Latina. São Paulo: Contexto, 2008.

DRIES, K. New York Fashion Week Was Chock-Full of White Models. Again. Jezebel, 17 de setembro de 2013. Disponível em: <http://jezebel.com/ new-york-fashion-week-was-chock-full-of-whitemodels-1326813852>. Acesso em: 20 de janeiro de 2016.

GOMES, N. L. Cultura negra e educação. Revista Brasileira de Educação, n. 23, p. 75-85, 2003.
JOHNSON, T. A.; BANKHEAD, T. Hair It Is: Examining the Experiences of Black Women with Natural Hair. Open Journal of Social Sciences, 2013.

LAGE, M. L. C.; SOUZA, E. M. Da cabeça aos pés: racismo e sexismo no ambiente organizacional. In: Congresso Brasileiro de Estudos Organizacionais, 4., 2016, Porto Alegre. Anais... Porto Alegre: SBEO, 2016. p.1-14.

MANO, M. K. Cadê os negros e índios da São Paulo Fashion Week? Centro de Estudos das Relações de Trabalho e Desigualdades, 16 de junho de 2011. Disponível em: <http://www.ceert.org.br/noticias/ mercado-de-trabalho-comercio-servicos/1152/cadeos-negros-e-indios-da-sao-paulo-fashion-week $>$. Acesso em: 20 de janeiro de 2016.

NASCIMENTO, M. C R.; OLIVEIRA, J. S.; TEIXEIRA, J. C.; CARRIERI, A. P. Com que Cor Eu Vou pro Shopping que Você me Convidou?. Revista de administração contemporânea, n.spe3, vol.19, pp.245-268, 2015.

NUNES, C. Blackface? Yes we can! .Blogueiras Negras. [S.l: s.n.]. Disponível em: <http:// blogueirasnegras.org/2013/04/18/blackface-yes-wecan/>. Acesso em: 7 out. 2015. , 18 abr. 2013.

O GLOBO. Emicida desfila coleção de sua grife, a LAB, na São Paulo Fashion Week. Disponível em: < http://oglobo.globo.com/ela/moda/emicidadesfila-colecao-de-sua-grife-lab-na-sao-paulofashion-week-20334287>. Acesso em: 20 nov. 2016.

RIACHUELO. Lançamento: Coleção Marrocos. Blog Estação, 11 de agosto de 2015. Disponível em: <http://www.riachuelo.com.br/blog/nas-lojas/ lancamento-colecao-marrocos/5572>. Acesso em: 20 de janeiro de 2016.

ROOKS, N. M. Hair raising: Beauty, culture, and African American women. [S.1.]: Rutgers University Press, 1996.

ROSA, A. R. Relações raciais e estudos organizacionais no Brasil. Revista de Administração Contemporânea, v. 18, n. 3, p. 240-260, 2014.

ROSA, A. R. Do Encontro das Águas ao Atlântico Negro: Organizaçãa, Difusão de Frames e os Limites do Ativismo Transnacional no Movimento Negro Brasileiro. 2011. 244 f. Tese (Doutorado em Administração Pública e 